\title{
Axial Crushing Behavior of Aluminum Square Tube with Origami Pattern
}

\author{
Prescilla Christy Albert ${ }^{1}$, Amir Radzi Ab Ghani ${ }^{1}$, Mohd Zaid Othman ${ }^{2} \&$ Ahmad Mujahid Ahmad Zaidi ${ }^{2}$ \\ ${ }^{1}$ Faculty of Mechanical Engineering, Universiti Teknologi MARA, Shah Alam, Malaysia \\ ${ }^{2}$ Department of Mechanical Enginering, Faculty of Engineering, National Defence University of Malaysia, Kuala \\ Lumpur, Malaysia \\ Correspondence: Mohd Zaid Othman, Department of Mechanical Engineering, Faculty of Engineering, National \\ Defence University of Malaysia, Kuala Lumpur, Malaysia. Tel: 60-12-4045-002. E-mail: zaid002@gmail.com
}

Received: October 15, 2015

Accepted: November 5, 2015

Online Published: January 7, 2016

doi:10.5539/mas.v10n2p90

URL: http://dx.doi.org/10.5539/mas.v10n2p90

\begin{abstract}
The study of axial crushing behavior is important in designing crashworthy structures especially in automotive applications. The axial crushing of thin-walled tube has better energy absorption capability. Thus, introducing milled geometrical shapes on thin-walled tube may improve the energy absorption performance. The improvement of the crush response is determined through the reduction of the Initial Peak Force (IPF) and the increase of the Specific Energy Absorption (SEA). This was done by employing origami pattern milled on the surface of thin-walled square tube which was investigated experimentally and numerically. The material used for the tube was aluminum alloy 6063-T5. The simulation results were validated by experiments which were conducted using INSTRON 3382 Universal Testing Machine and INSTRON DYNATUP 8250 Drop Hammer Machine. The numerical simulation then progressed by varying parameters such as dimensions and configurations of the origami pattern on the square tube. ABAQUS finite element (FE) software was used to conduct the numerical simulation. The result of employing the origami square pattern on square tube is expected to improve the crush response by lowering the IPF and increasing the SEA. The obtained results were then compared with the conventional square tube where the origami pattern on square tube enhanced the crush performance.
\end{abstract}

Keywords: thin-walled tube, origami pattern, square tube, axial crushing, energy absorption

\section{Introduction}

Thin-walled structure has been widely used in automotive field as energy absorbers due to its stable collapsible nature. Therefore, thin-walled tube is more efficient and flexible and it offers better energy absorption capability (Fan et al., 2011). The crumple area of thin-walled structure absorbs majority of the crash impact energy hence improving the safety of driver or passengers. Energy absorber is a system that can absorb impacted energy via elastic and plastic deformations. The device must be able to absorb major energy of impact in an irreversible manner in order to design a collapsible energy absorber (Alghamdi, 2000).

The conventional square tube is the most popular design for the energy absorber devices. There were studies about the square tube with dents and grooves as the energy absorber devices where the crush performance of this system has improved compared to the conventional square tube. Now, researchers come out with new idea and the square tube with origami pattern started to be introduced so as to improve the crush performance of the energy absorber as well as to improve the safety of the system (Song et al., 2012).

In general, thin-walled tubes are quite popular in design and commonly used as energy absorbers in various industries. The different in cross-sections of thin-walled tubes are generally used as energy absorbing structural components in large industrial products especially in automotive and transportation (Zhang et al., 2007; Song et al., 2012). Circular and rectangular tubes have similar load-displacements curves under axial loading where the axial force first reaches the initial peak which is then followed by a drop and fluctuating mean force. The almost long fluctuating force region after the IPF endows the tubes with high energy absorption capacity. The higher SEA of the energy absorber often regarded as more efficient (Zhang et al., 2007; Song et al., 2012; Lu \& Yu, 2003; Zhang et al., 2008). 
The introduction of patterns to the thin-walled tube will altered the crushing mode in order to achieve better energy absorbing performance (Song et al., 2012). This will improve the energy absorption characteristic where the patterns were generated by appropriate arrangement of a set of identical basic elements. Patterned tube have lower initial peak force and more uniform crushing pattern than conventional tubes which makes them more suitable as energy absorbers. The energy absorption characteristics of the square tubes under axial loading are strongly dependent on the collapse modes. You \& Cole (2006) discovered that by using different patterns (see Figure 1) it was possible to create bi-stable thin-walled booms that are strain-free in both folded and fully expanded configurations and it was observed that the patterns may also be used to design tubes with better energy absorption. The behaviour of the absorber can be controlled by introducing initial geometrical imperfections such as corrugation, groove and some other imperfections and resulted in the reduction of initial buckling force of around 30\% (Zhang et al., 2007; Song et al., 2012; Abramowicz \& Jones, 1985; Fan et al., 2011; Lu \& Yu, 2003).
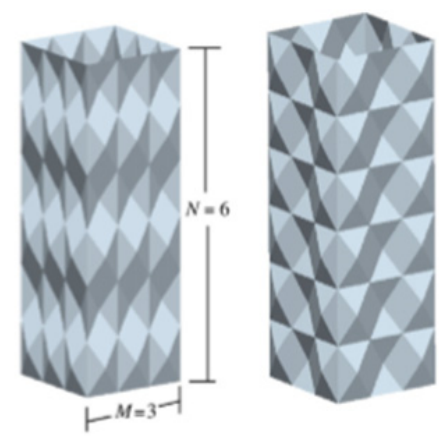

Figure 1. Basic pyramid elements' pattern with inward and outward configuration (You \& Cole, 2006)

Aluminium tube works as an impact structure and absorb most of impact energy which is then transmitted into other frame parts. Therefore, the frame parts should be designed to promote folding or bending to more effectively absorb impact energy. Figures 2 and 3 show the computer-simulated test based on the work conducted by past researchers (Sunghak Lee et al., 1999). As a result, Model B with 6 dents showed the best absorption where the folding formed precisely at the desired sites.

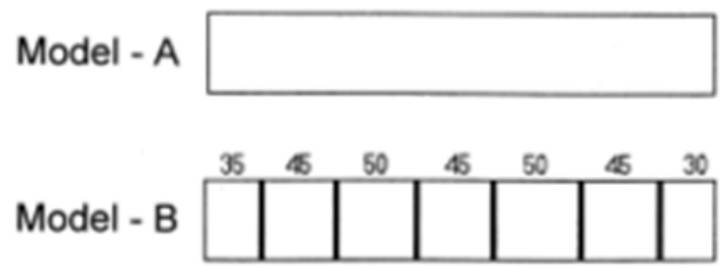

Figure 2. Schematic diagram of Model A (undented model) and B (dented model) used in the computer-simulated compressive test (Sunghak Lee et al., 1999)
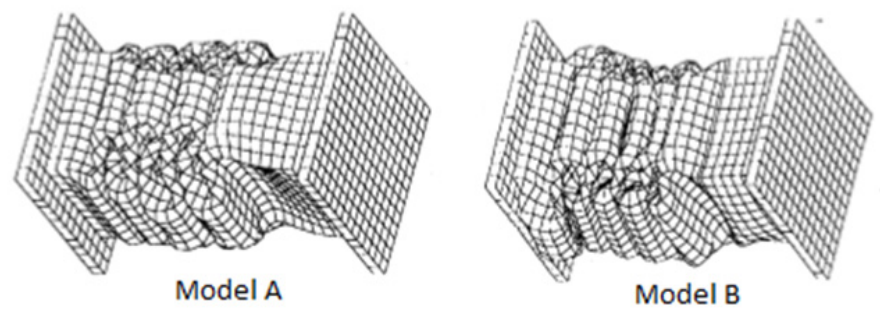

Figure 3. Deformed shapes of Model A and B (Sunghak Lee et al., 1999) 
Thin-walled components play a major key structural component of the majority of transportation vehicles. During a crash event, in order to meet stringent integrity requirements, a number of structural components must sustain the abnormal loading. At the same time, for the safety limit requirement, the other components must dissipate impact energy in a controlled manner that limits the deceleration of a vehicle. The majority of structural components of land, sea and air are designed as thin-walled structures. In the early 1960s, the new demanding area of engineering analysis has been opened in all sectors of transportation industry by the automotive safety regulations. For example, in the case of car accidents, the structure of passengers compartments are required to sustain crash loading without excessive deformations that compromise safety of passengers (Abramowicz, 2003).

Origami technique has been employed to generate patterns on thin-walled structures. Thin-walled tubes with origami pattern are popular design for the energy absorbing devices and would minimize the initial peak (Katangoori et al., 2013; Song et al., 2012; Abramowicz \& Jones, 1985; Ghani et al., 2013). Energy absorbing devices are design to be crashworthy especially in motor vehicle and aircraft. The purpose is to absorb kinetic energy during collision. Metallic thin-walled square tubes with pre-engineered patterns in the surface have been shown better energy absorption capacity than conventional square tubes with no modification to their surfaces (Zhang et al., 2007; Katangoori et al., 2013; Song et al., 2012).

Yamashita studied dynamic axial crushing of an aluminium tubular structure with hat-shaped configuration. A buckling initiator consisting of two solid blocks attached to the side wall at a specified height of the structure was used to initiate the first plastic buckling lobe. The solid blocks provided inertia force that caused wall bending (Yamashita et al., 2012). Nia studied numerically and experimentally the effect of collapse initiators on energy absorption characteristics of aluminium square tubes under oblique quasi-static loading. Collapse initiators were in the form of cuttings on tube corners. The location and number of initiators, and loading angles were varied. Numerical results showed that the collapse initiators changed the tube deformation mode from global buckling to progressive buckling. The initial peak force was substantially reduced, hence increasing the crush force efficiency (Nia et al., 2012).

Jandaghi and Marzbanrad analytically and experimentally investigated the crush behaviour of aluminium 6061 segmented circular tubes. The segmented tubes were called Tailor-made Tubes (TMTs) where the thickness and mechanical properties of the wall were varied along the length of the tube. Results showed that the length and thickness of each tube segment had significant influence on crush force and energy absorbing performance. The TMTs had higher energy absorption per unit crush length and mass compared to the plain tube. The TMTs also exhibited significant reduction in initial peak and mean forces (Jandaghi \& Marzbanrad, 2012). Tarlochan described a computationally aided design process of a thin walled structure subjected to axial and oblique impact. Several different cross sectional shapes were studied and a multi criteria decision making (MCDM) process was utilised to optimise the structure (Tarlochan et al., 2013). Kim experimented with combinations of aluminium and CFRP square hollow tubes to absorb axial impact load. Laminate sequence and fibre orientation had significant effect on the crush force efficiency and specific energy absorption (Kim et al., 2014). Ma investigated the effect of carbon and aramid fibre layer and heat treatment on the energy absorption of filament wound composite tubes. It was found that the heat treatment improved the energy absorption of carbon/aramid tubes (Ma et al., 2015).

The main issue for the axial loadings of tubular structures is the initial peak force (IPF). The reason for the occurrence of serious injury to the occupant and damage to the protected goods is due to the high IPF. Therefore, it is necessary to reduce the initial peak force to prevent and reduce the unwanted injury and damage from occurring. This paper investigates the utilisation of origami pattern milled onto the walls of square aluminium tube in order to enhance the energy absorption performances by reducing the initial peak force and increasing the specific energy absorption.

The crush force efficiency (CFE) is the expression of the impact response of the structure. This is important in measuring the uniformity of collapse force. The percentage of CFE calculated from the ratio of mean force to the peak force.

$$
C F E=\text { Mean force/Peak force }
$$

Specific energy absorption (SEA) is the ratio of total energy absorbed divided by the mass of the material where the mass can be calculated by the volume of structure times with the density of the material.

$$
\text { SEA }=\text { Energy absorption/Mass }
$$




\section{Method}

\subsection{Modelling and Simulation}

The origami pattern was constructed on the surface of thin-walled tube and the model was created using ABAQUS software for the purpose of finite element analysis simulation process and also CATIA software for the purposes of modelling and fabrication process (see Figure 4, 5 and Table 1). The conventional square tube as well as top and bottom plates were also modelled in ABAQUS software. In the finite element analysis simulation, the square tube with origami pattern will be analysed with different dimension and configuration of the origami pattern. In the experimental method, the compression of square tube with origami pattern was only performed for one selected pattern.

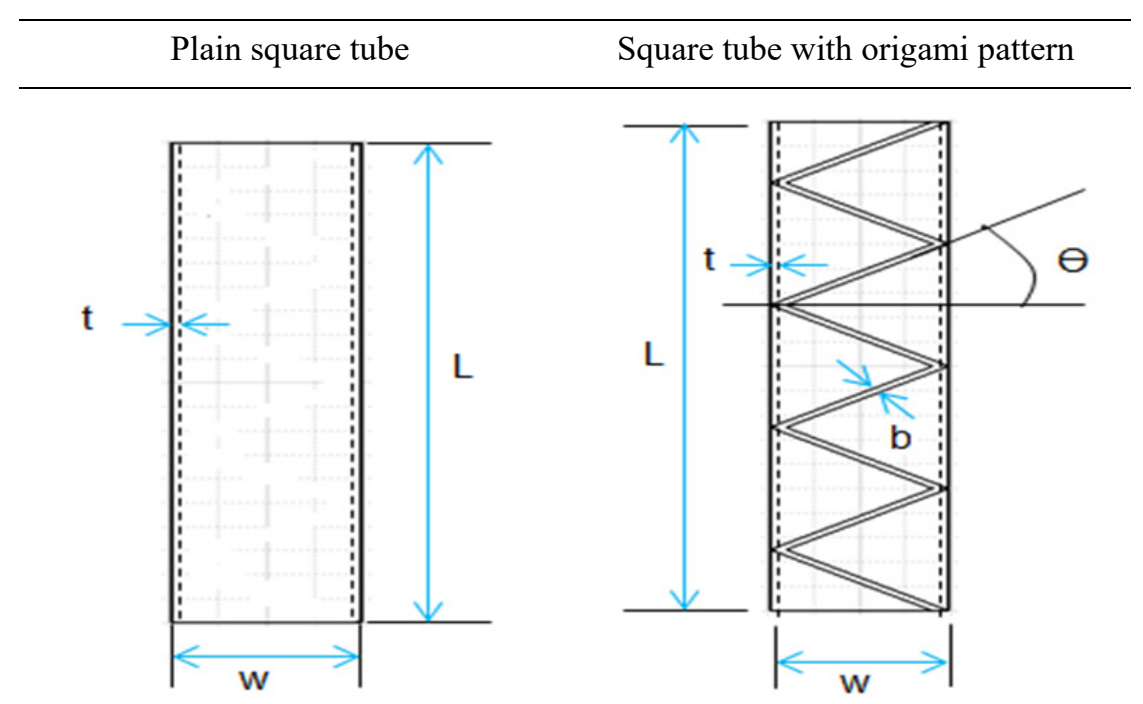

Figure 4. Design configurations for the plain square tube and the square tube with origami pattern

Table 1. Design dimensions for the plain square tube and the square tube with origami pattern

\begin{tabular}{lcc}
\hline \multicolumn{1}{c}{ Parameters } & Plain square tube & Square tube with origami pattern \\
\hline Length, L (mm) & 200 & 200 \\
Width, w (mm) & 39 & 39 \\
Thickness, t (mm) & 1.5 & 1.5 \\
Width of grooves, b (mm) & -Nil- & 4 \\
Depth of grooves, d (mm) & -Nil- & 0.6 \\
Grooves angle, $\Theta($ degree) & -Nil- & 35.135 \\
\hline
\end{tabular}



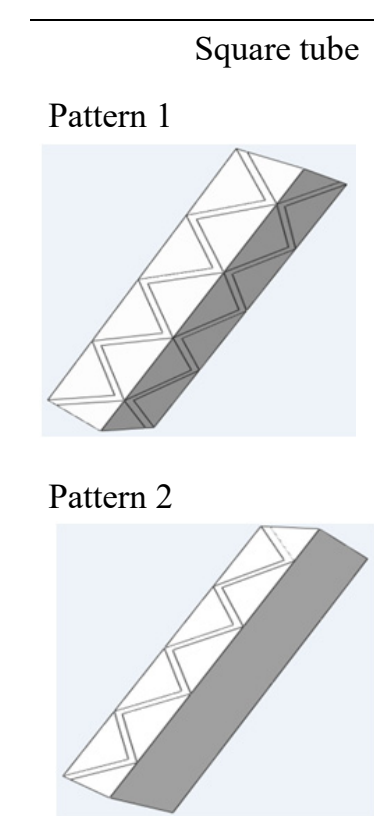

$\theta=32.66^{\circ}$

$\mathrm{s}=50 \mathrm{~mm}$

$\mathrm{b}=4 \mathrm{~mm}$

The pattern only employed on two opposing faces.

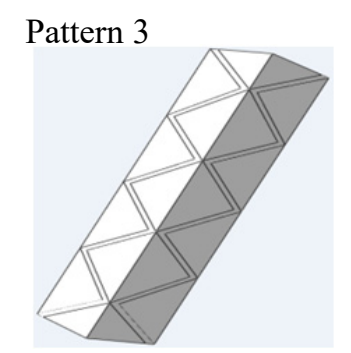

$\theta=27.15^{\circ}$

$\mathrm{s}=40 \mathrm{~mm}$

$\mathrm{b}=3 \mathrm{~mm}$

The pattern is employed on four faces of the square tube.

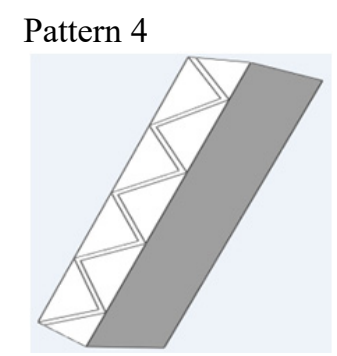

$\theta=27.15^{\circ}$

$\mathrm{s}=40 \mathrm{~mm}$

$\mathrm{b}=3 \mathrm{~mm}$

The pattern only employed on two opposing faces.

Figure 5. Design for different pattern parameters of square tube

\subsubsection{Finite Element Modelling}

a) Part Module

In this module, geometry of individual parts was created. The geometry of square tube with origami pattern, the conventional square tube, top plate, and bottom plate will be modelled in this section where the type of geometry was defined as well as its dimensions (see Figure 6). 


\begin{tabular}{c|l}
\hline \multicolumn{1}{c|}{ Image } & \multicolumn{1}{c}{ Details } \\
\hline Top plate & $\begin{array}{l}\text { Width: } 100 \mathrm{~mm} \\
\text { Length: } 100 \mathrm{~mm} \\
\text { Gottom plate }\end{array}$ \\
Geometry type: Discrete rigid \\
Win-walled square tube
\end{tabular}

Figure 6 . The dimensions of the square tube

b) Properties Module

The mechanical properties of for both types of the square tubes were assigned under the properties module and are made from Aluminium AA6063-T5 (see Table 2).

Table 2. The mechanical properties of the square tube made from Aluminium AA6063-T5

\begin{tabular}{|c|c|}
\hline Density, $\rho$ & $2790 \mathrm{~kg} / \mathrm{m}^{3}$ \\
\hline \multirow{2}{*}{ Elasticity properties } & Young's Modulus $=73.1 \mathrm{GPa}$ \\
\hline & Poisson's ratio $=0.35$ \\
\hline \multirow{3}{*}{ Plasticity properties } & Yield strength $=180 \mathrm{MPa}$ \\
\hline & Ultimate tensile strength $(\mathrm{UTS})=220 \mathrm{MPa}$ \\
\hline & Plastic strain at UTS $=0.1$ \\
\hline
\end{tabular}

c) Assembly Module

The top plate, bottom plate and the test specimen i.e. square tube with and without the origami pattern were positioned according to their respective location based on the experimental test arrangement (see Figure 7). The bottom plate was placed according to the base flat rigid plate of the experimental test. The test specimen was then located on top of the bottom plate in the vertical direction. Finally, the top plate was positioned on top of the test specimen. Force is applied to the tube by the downward movement of the top plate. 


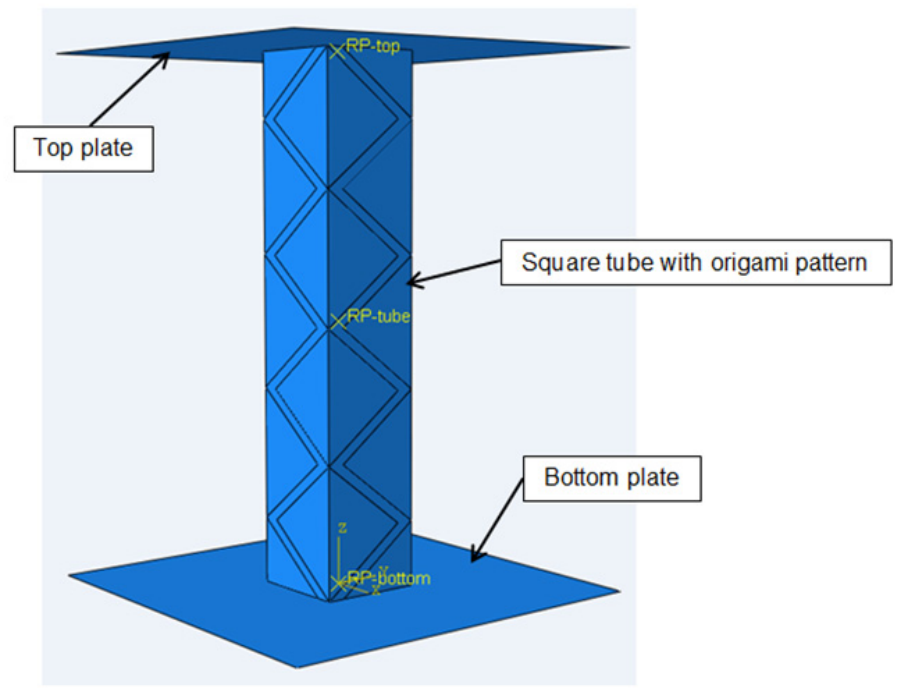

Figure 7. The complete arrangement of the bottom plate, test specimen and top plate

\subsection{Experimental Procedures}

The fabrication of square tube with origami pattern begins with raw material of aluminium square tube which was cut into desired lengths by using abrasive cutting tools. The top and bottom edges of square tube were finished into the respective lengths by using the milling machine. The origami pattern was created by using the computer numerical control (CNC) machine which requires drawing from CATIA computer aided design (CAD) software. The average lead time for grooves fabrication of square tube is about 5 minutes per surface; hence the total lead time for one square tube is about 23 minutes including the idle time. The faces of square tube must be totally flat. The spirit level ruler is used to check the straightness and flatness of top and bottom tube faces and it must be done on the stable table top.

The experimental tests were conducted to validate computer simulation results. Thus, two types of test need to be conducted i.e. the static compression test and the impact test. The static compression test was performed by using INSTRON 3382 Universal Testing Machines as shown in Figure 8 and the impact test is performed using INSTRON DYNATUP 8250 Drop Hammer Machine as shown in Figure 9 with the top plate mass set at 36.34 $\mathrm{kg}$. The velocity for static compression experiment is defined to be $10 \mathrm{~mm} /$ minute with crushing distance of $70 \%$ the tube length. For impact experiment, the velocity is set at $6 \mathrm{~m} / \mathrm{s}$.

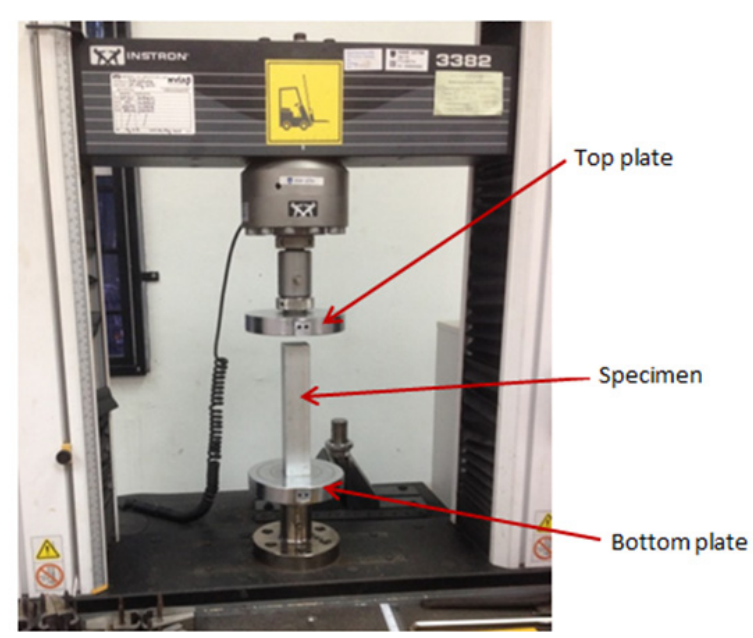

Figure 8. An INSTRON 3382 Universal testing machine 


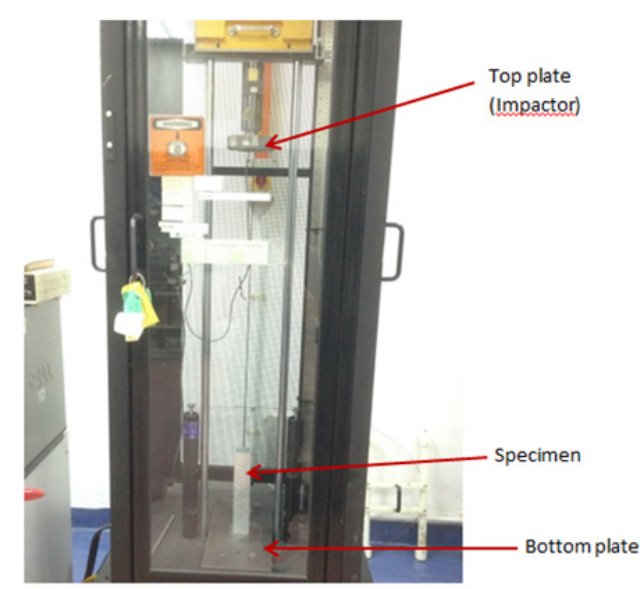

Figure 9. An INSTRON DYNATUP 8250 drop hammer machine

\section{Results and Discussion}

\subsection{Validation of Simulation Results}

For the experimental tests, a minimum of five samples were used for each test. Figure 10 shows the experimental and simulation force-displacement curves of the conventional square tube subjected to axial static loading. Simulation result compared favorably with the experimental result. Both curves show high IPF followed by lower fluctuating mean forces. Experimental values were slightly lower than the simulation values. This could be due to specimen imperfections in the form of tube geometry and material properties.

Figure 11 shows the experimental and simulation force-displacement curves of the square tube with origami pattern subjected to axial static loading. Simulation result showed good agreement with the experimental result. Similarly, experimental values were lower than simulation values due to the same reasons as above. However, additional machining work to create the origami pattern resulted in stress concentrations that may further weaken the tube. Both simulation and experimental results have shown that the tube with origami pattern has lower IPF compared to the plain square tube. This result demonstrates the effectiveness of the origami pattern in reducing the IPF of the square tube subjected to axial loading.

\section{Graph of Force versus Displacement of Conventional Tube for Axial Static Loading}

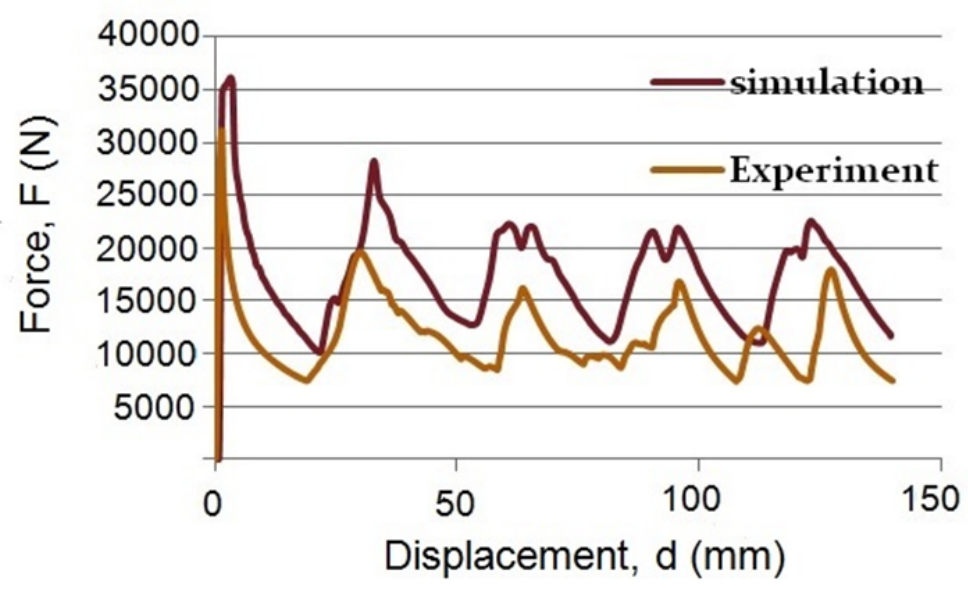

Figure 10. Graph of force versus displacement for axial static loading of conventional square tube 


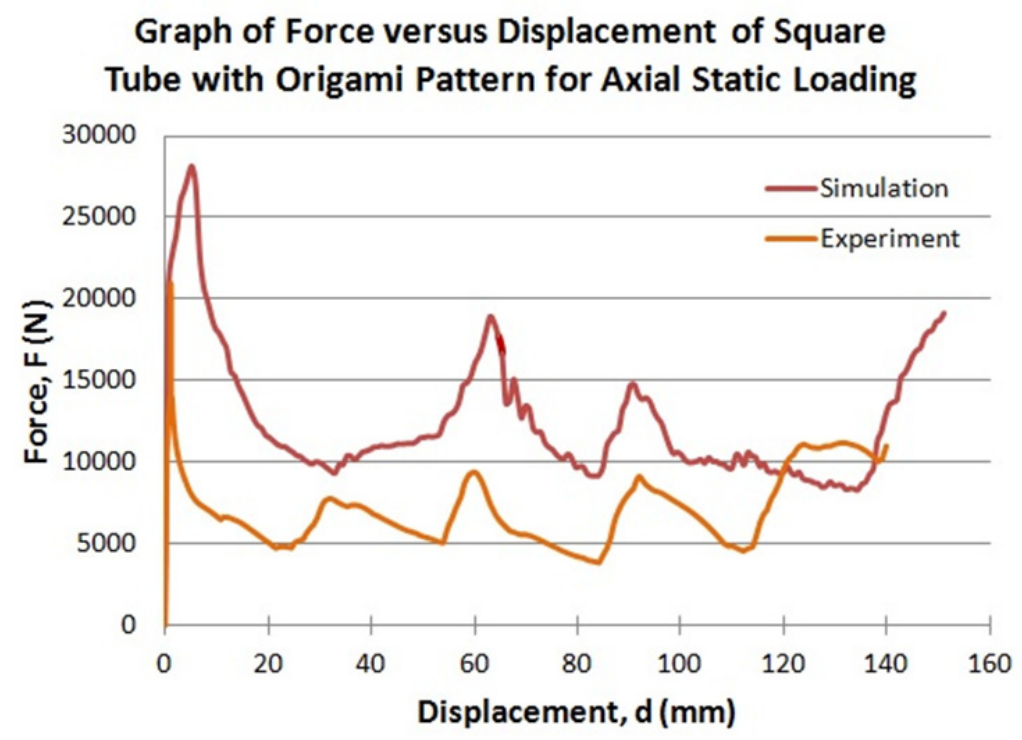

Figure 11. Graph of force versus displacement for axial static loading of square tube with origami pattern

Figure 12 shows the experimental and simulation force-displacement curves of the conventional square tube subjected to axial impact loading. Simulation result shows similar trend as experimental result with the simulation result slightly over predicting the IPF, fluctuating mean forces and crush distance. Also simulation result indicates that the impactor has rebounded off the tube at the end of travel. This is shown as decreasing displacement value. Experimental result shows highly fluctuating forces which gradually stabilized towards the end of the travel. This is due to the stress wave propagation in the contacting bodies. Figure 13 shows the experimental and simulation force-displacement curves of the square tube with origami pattern subjected to axial impact loading. Simulation result shows similar trend as experimental result with the experimental result having slightly higher IPF. Simulation result also shows a considerable longer crushing distant as compared to experiment with a slight rebound at the end of travel. This could be due to the manufacturing inconsistency of the origami pattern which resulted in a different fold shape as compared to the simulation result. Both simulation and experimental results have shown that the tube with origami pattern has lower IPF compared to the plain square tube. Therefore, further parametric study of the tube with origami pattern was pursued using simulation technique only.

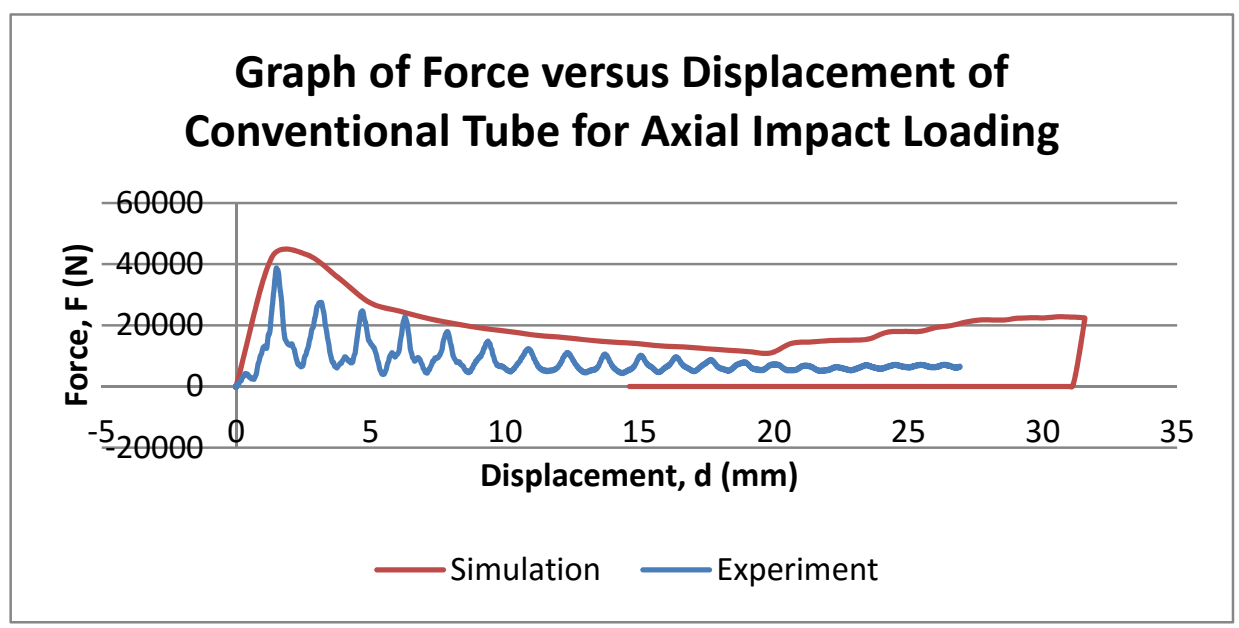

Figure 12. Graph of force versus displacement for axial impact loading of conventional square tube 


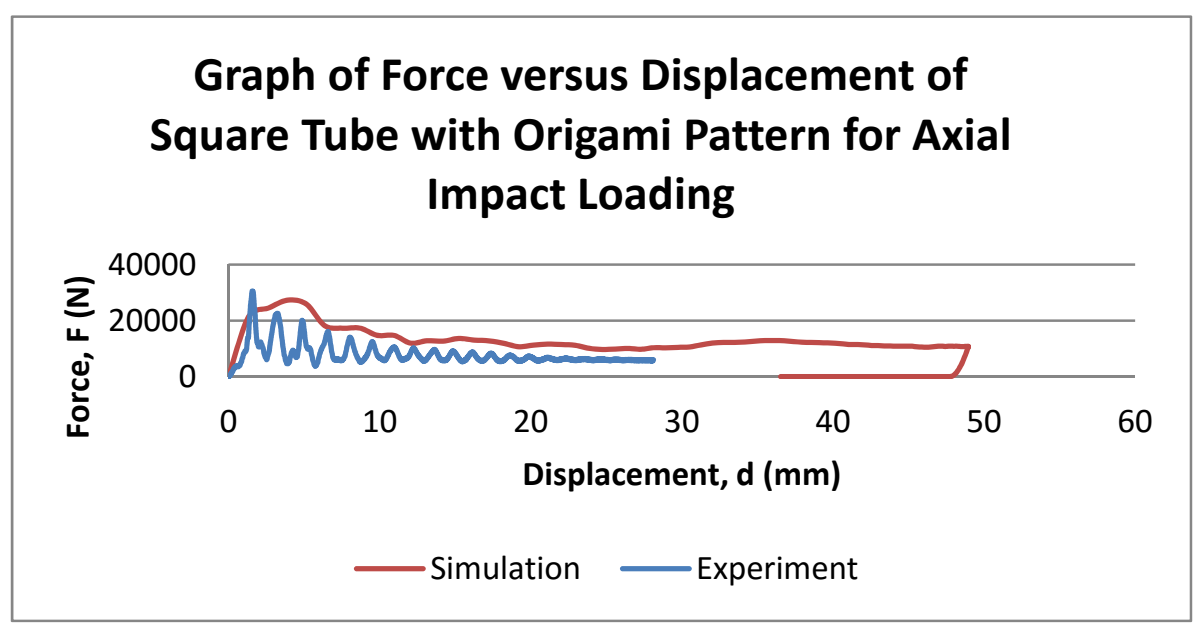

Figure 13. Graph of force versus displacement for axial impact loading of square tube with origami pattern

\subsection{Axial Loading Energies of Conventional and Origami Pattern Square Tube Results}

The energy curves for axial static and impact loading for the simulation of the conventional square tube are as shown in Figure 14 and Figure 15, respectively.

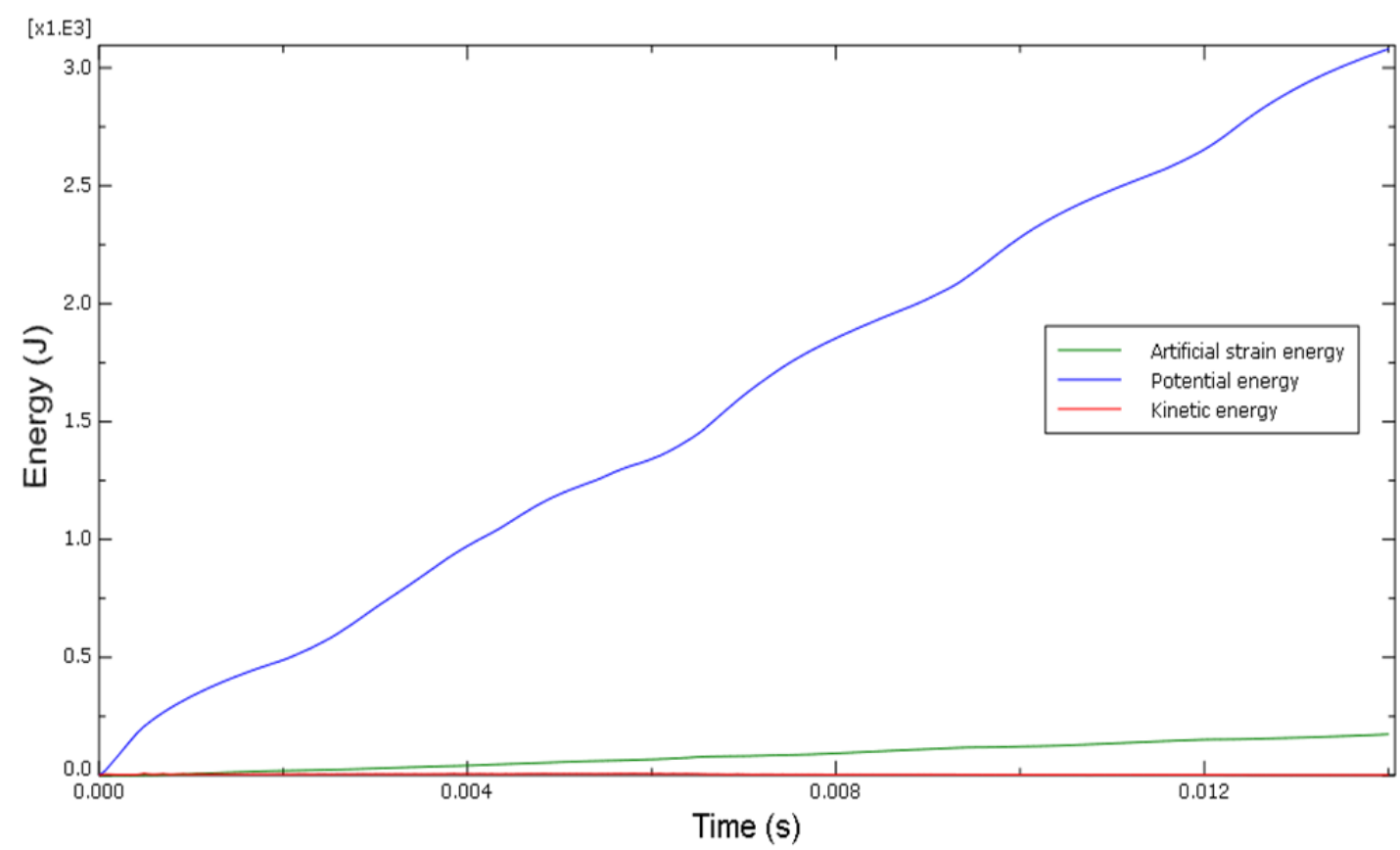

Figure 14. Energy variable curves for conventional square tube subjected to static axial loading 


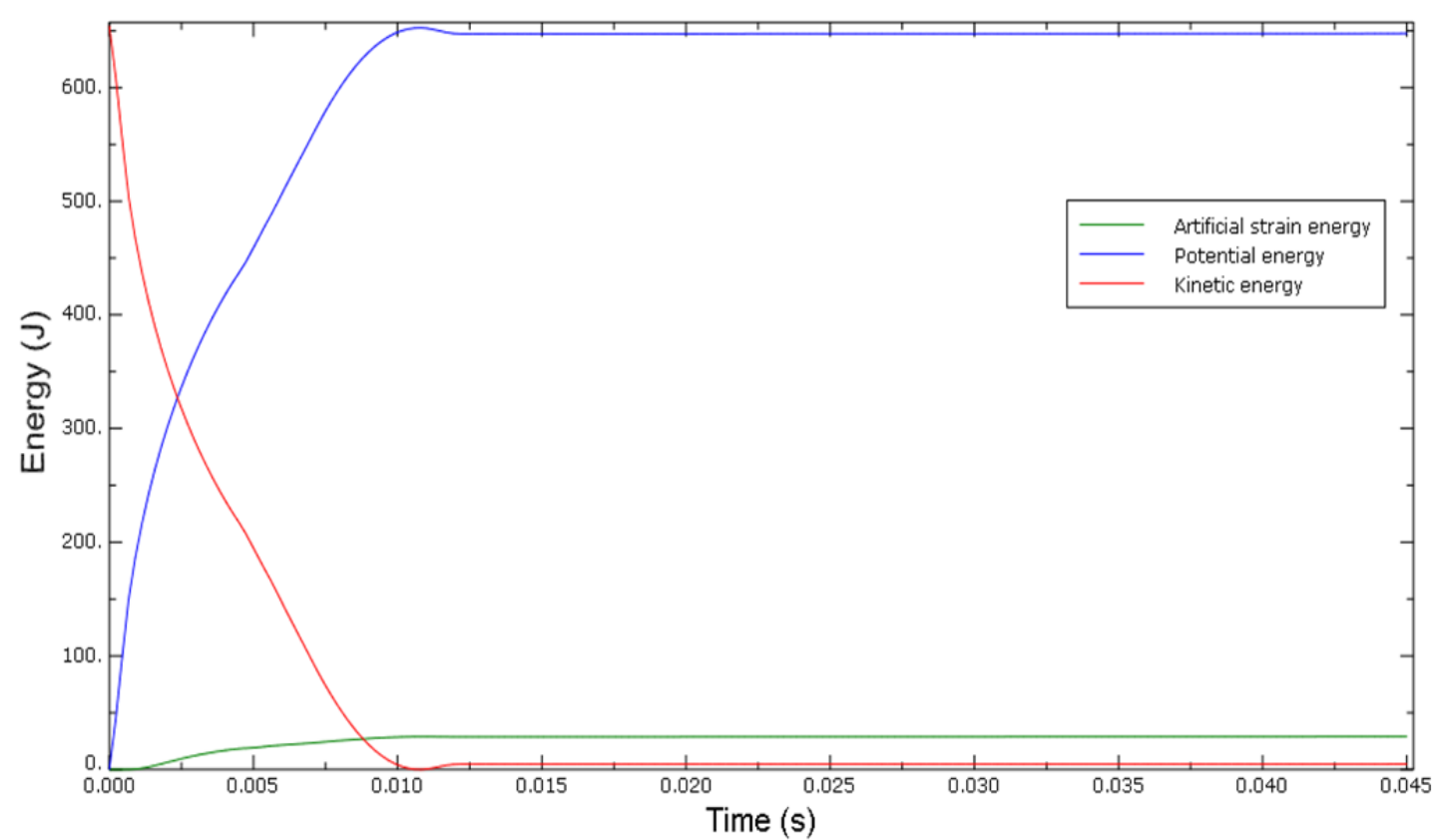

Figure 15. Energy variable curves for conventional square tube subjected to impact loading

The energy curves for axial static and impact loading for square tube with origami pattern are as shown in Figure 16 and Figure 17, respectively.

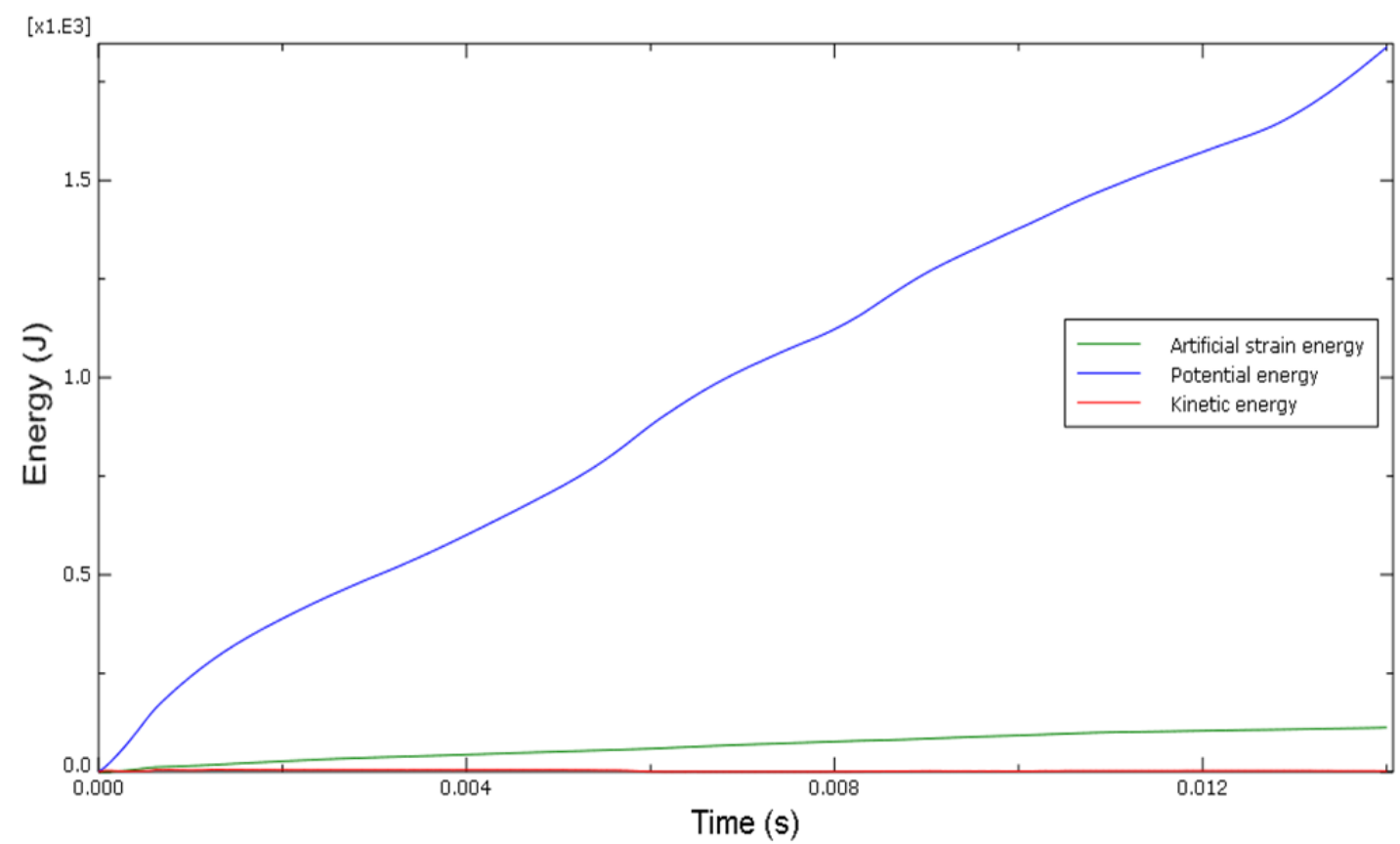

Figure 16. Energy variable curves for square tube with origami pattern subjected to static axial loading 


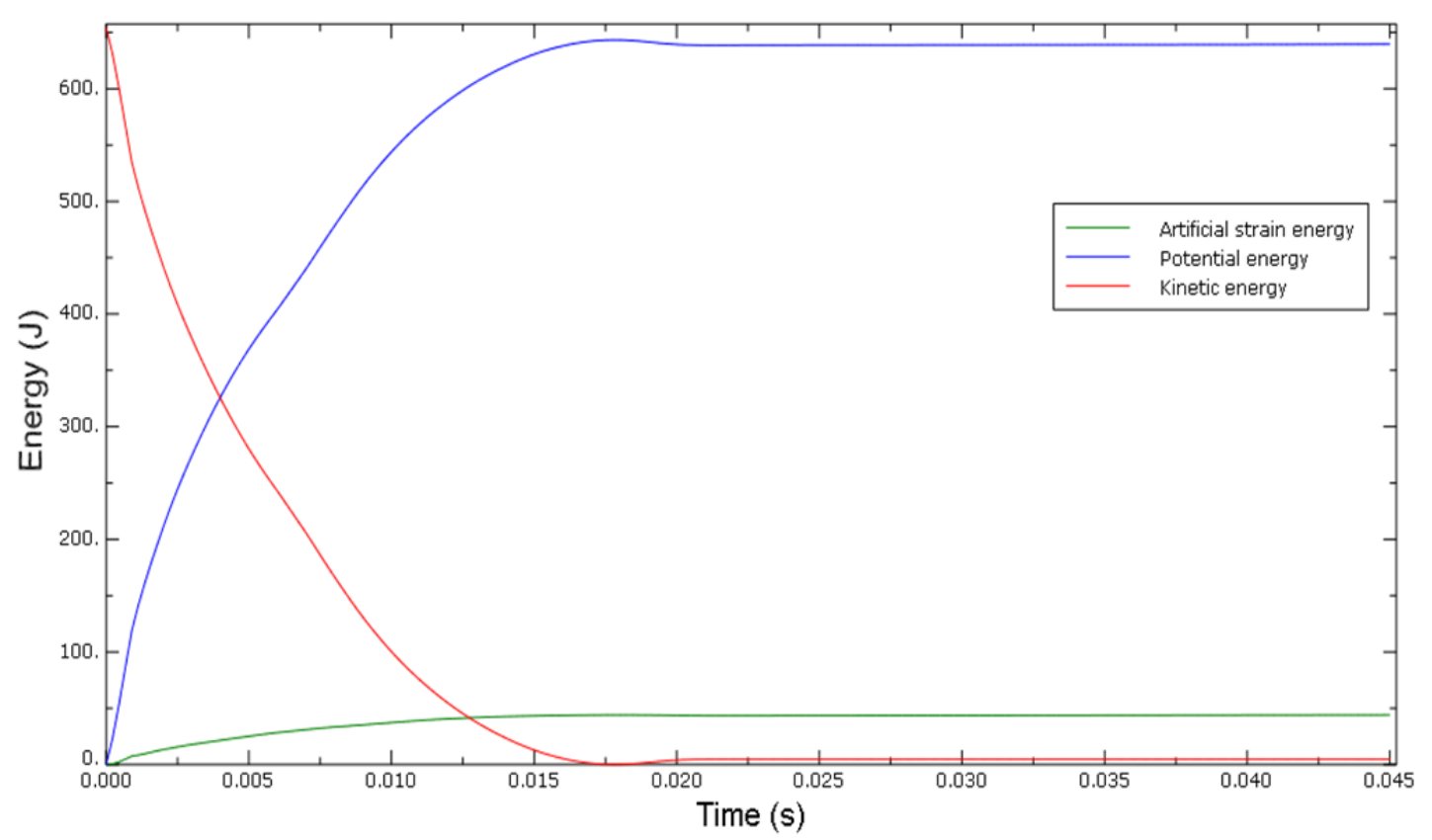

Figure 17. Energy variable curves for square tube with origami pattern subjected to impact loading

The variations of energy included were artificial strain energy, potential energy and kinetic energy. Minimal kinetic energy for the static simulations indicated that the loading was quasi static where inertia effect was negligible. The low artificial strain energy indicated that element distortion was within acceptable limit. For the impact simulation, the kinetic energy of the impactor is dissipated by plastic deformation of the tube. This is shown as decreasing value of kinetic energy curve and increasing value of potential energy curve.

\subsection{Failure Modes Results}

Figure 18 shows the deformation modes from experimental and simulation for axial static loading of square tubes. Both conventional square tube and square tube with origami pattern were compressed to about $70 \%$ of its initial height. In the axial static loading, the deformation mode for conventional square tube started with concertina modes which begin to crush from the top in experimental test while in the simulation, the visualization showed that the crush started from the bottom of the conventional square tube. The deformation modes for square tube with origami pattern were concertina patterns with irregular arrangement both in experimental as well as simulations.

Figure 19 shows the deformation modes from the experimental and simulation data for axial impact loading for both types of square tubes. In the axial impact loading, the deformation modes for both conventional square tube and the square tube with origami pattern had few differences in simulation and experimental methods. For the conventional square tube, the deformation mode consisted of only one layer fold which crushed off from the top area in the experimental test, while in the simulation test, the deformation of the square tube started from the bottom area. As for the square tube with origami pattern, the simulation showed that the deformation modes crushed around the top area of the square tube. Conversely, the deformation modes for experimental deformation were different for three square tubes with origami pattern specimen where specimen 1 and 2 showed nearly similar location of the crush while specimen 3 showed the crush in the bottom area of the tube. All of the discrepancies experienced by all 3 origami pattern square tubes obtained from the experimental tests might due to the imperfection of all 3 specimens which might had occurred during the fabrication session. 


\section{Conventional square tube}

Experiment

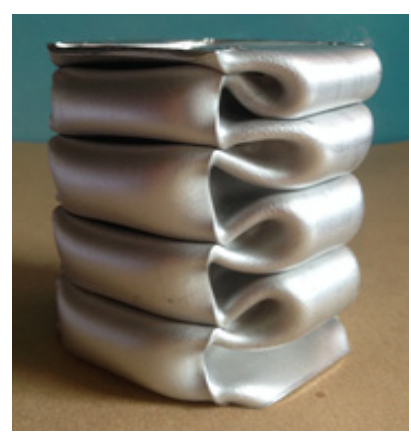

Simulation

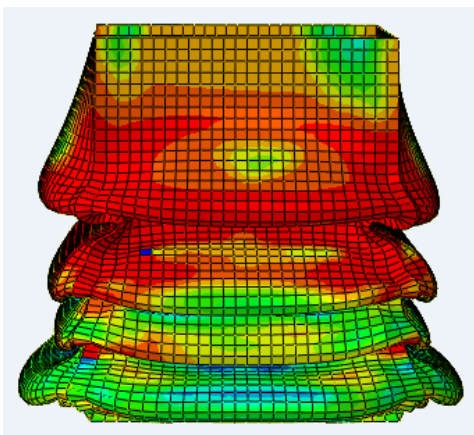

Square Tube with Origami Pattern

Experiment

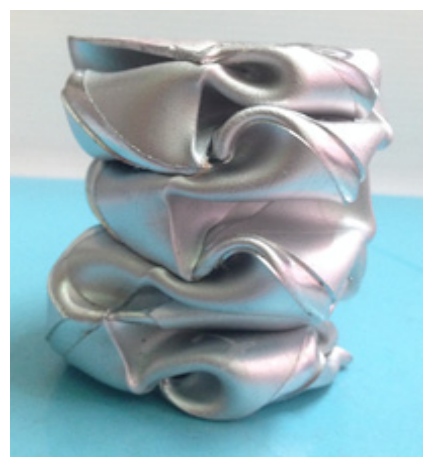

Simulation

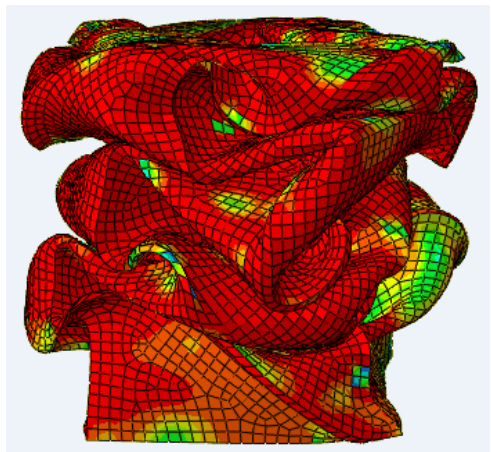

Figure 18. Failure deformation modes for the experimental and simulation test for both types of square tubes (static axial loading)

\section{Conventional Tube}

Experiment

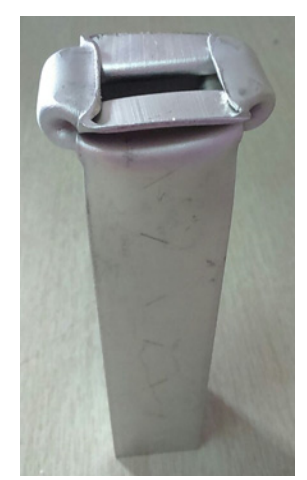

Simulation

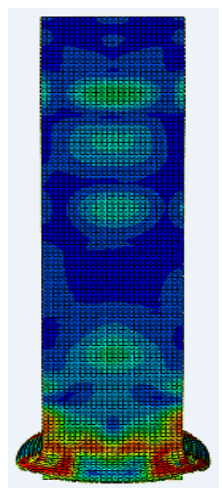

Square Tube with Origami Pattern 

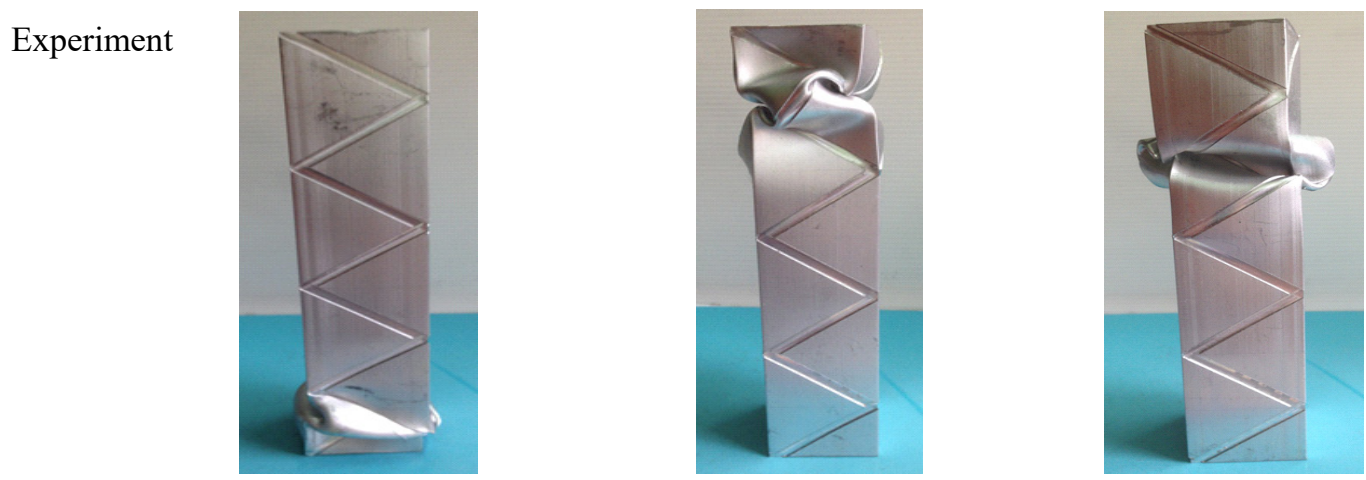

Simulation

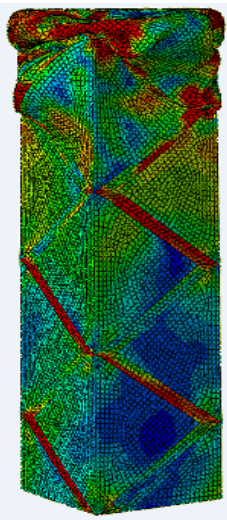

Figure 19. Failure modes from experiment and simulation for axial impact loading

Figure 20 shows the axial static response for conventional square tube and the square tube with different origami pattern parameters. The conventional/plain square tube had the highest IPF compared to the square tube with different origami patterns. Pattern 1 shows the lowest IPF while pattern 4 shows the highest IPF among all patterns. The origami patterns reduce the structure's stiffness on the square tube therefore it is easier for the square tube to be crushed with lower and more uniform force. Based on the results from Figure 20, the employment of origami pattern on square tube succeeds in reducing the IPF.

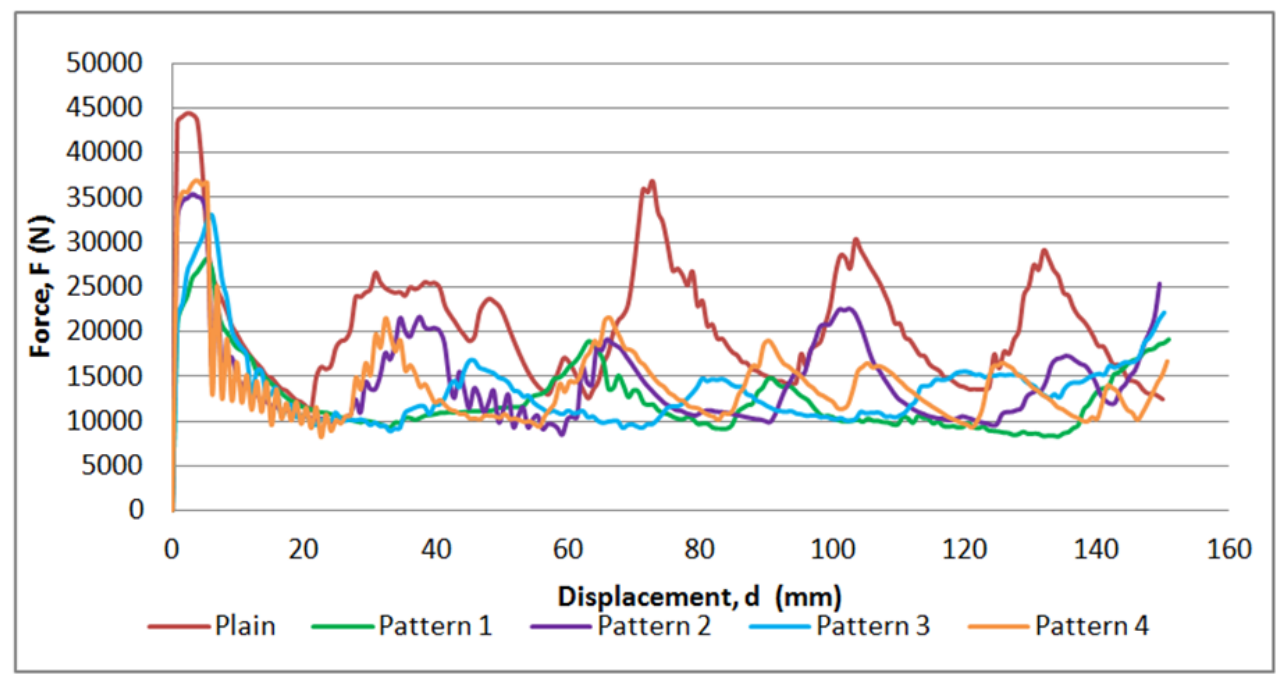

Figure 20. The graph of force versus displacement for plain square tube and square tubes with different dimensions and configurations of origami pattern under static axial loading 
Figure 21 shows the failure modes for the origami pattern parameters of the square tube. Patterns 2,3 and 4 had almost similar in deformation modes compared to pattern 1 which deformed while following the grooves of the pattern.

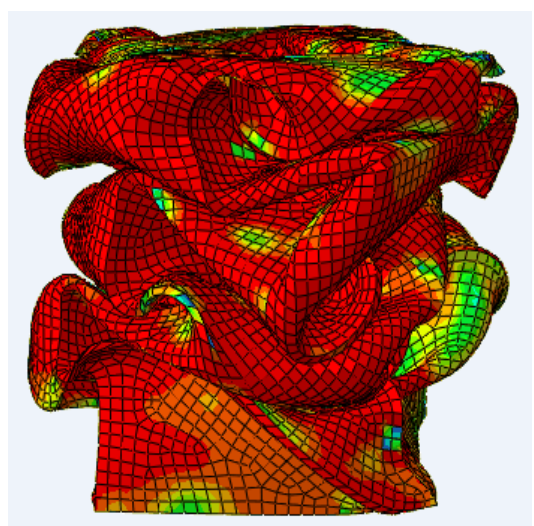

Pattern 1

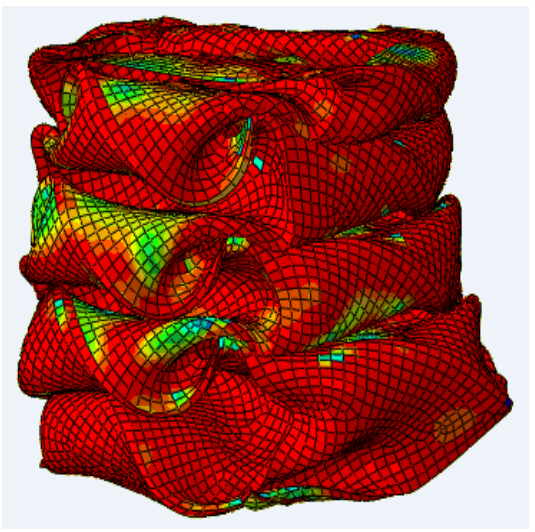

Pattern 3

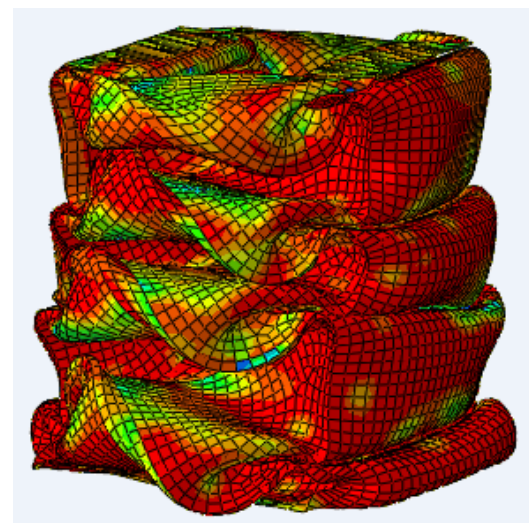

Pattern 2

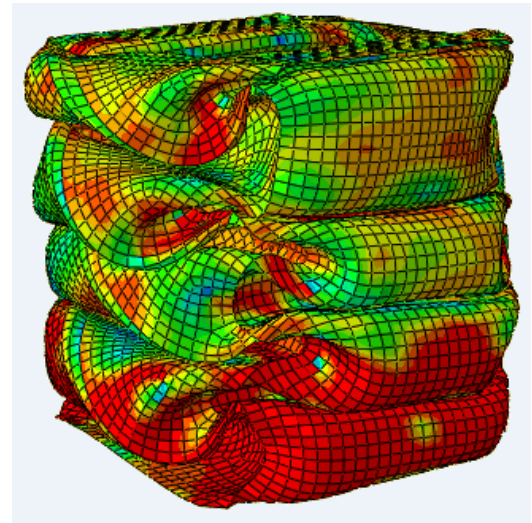

Pattern 4

Figure 21. Failure modes of the square tube with origami pattern with different dimension and configuration for static axial loading

The simulation of square tube with different pattern parameters proceeded to axial impact analysis and Figure 22 shows the axial impact response for plain/conventional square tube and the square tube with different origami pattern parameters. The plain/conventional square tube had the highest IPF compared to the square tube with different origami patterns. Pattern 1 shows the lowest IPF, while pattern 4 showed the highest IPF among all patterns. Similar to the static analysis, the reduction in IPF occurred because of the employment of origami pattern which reduced the stiffness on the square tube that eased the crushing process of the square tube. Thus, Figure 22 showed that the employment of origami pattern on square tube had managed to lower the IPF of square tube under axial impact loading. 


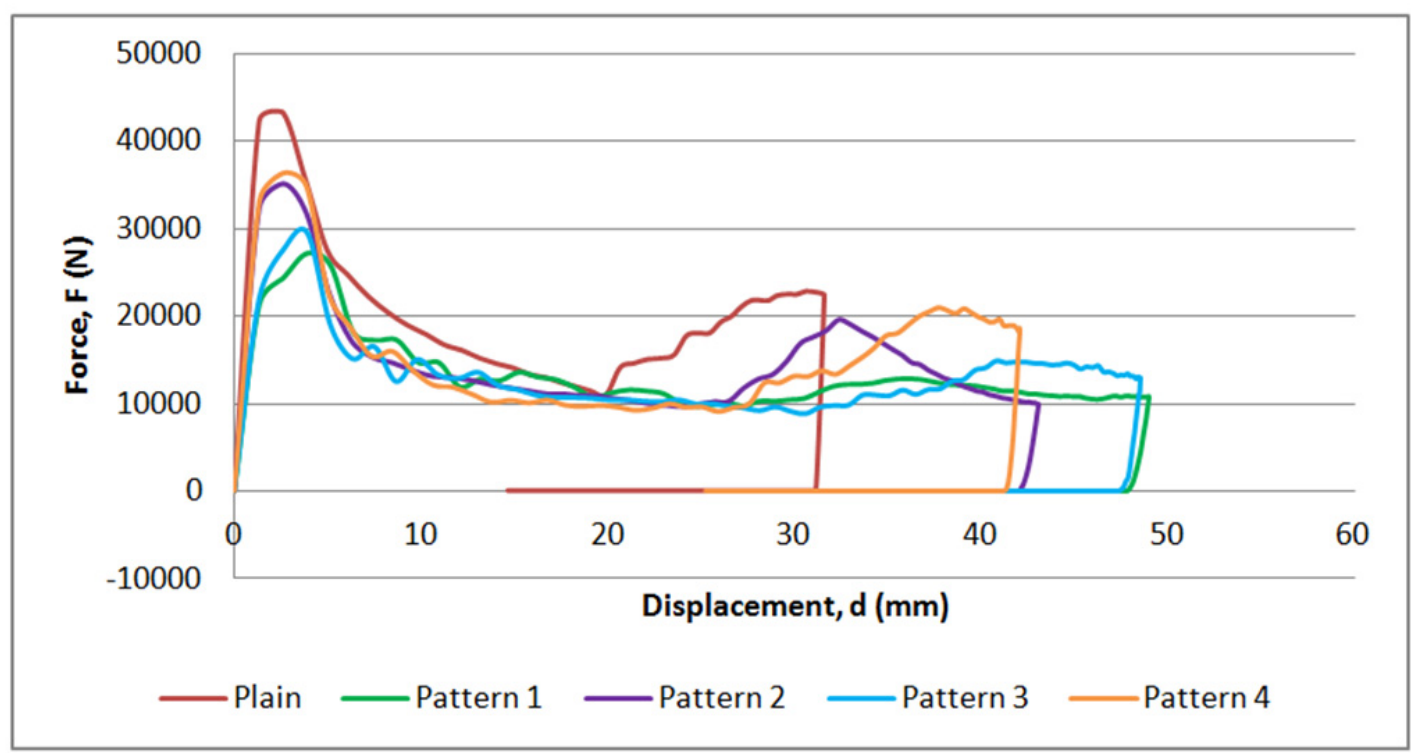

Figure 22. Graph of force versus displacement for conventional/plain square tube and square tubes with different dimension and configuration of origami pattern under axial impact loading

Figure 23 shows the failure modes for the origami pattern parameters of the square tube. It can be seen that the pattern 1 and 3 which employed origami pattern on both face on the square tube deformed from the top area of the square tube. For patterns 2 and 4, the deformation was initiated at the bottom area of the origami pattern square tube.

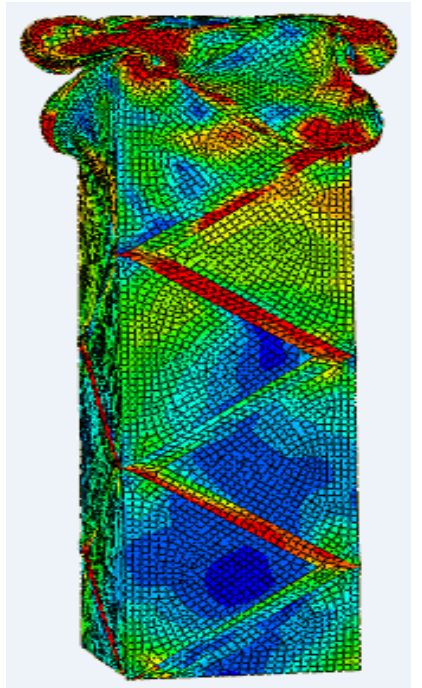

Pattern 1

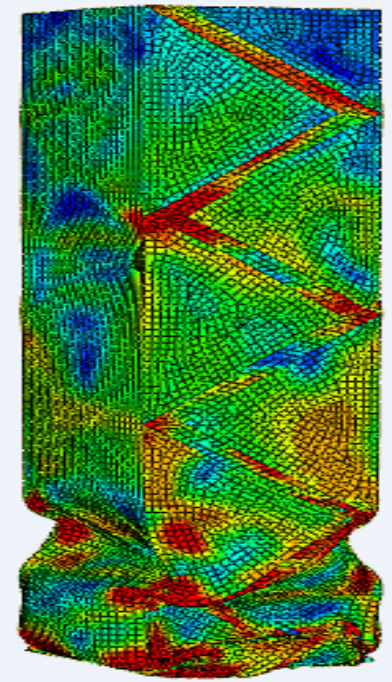

Pattern 2 


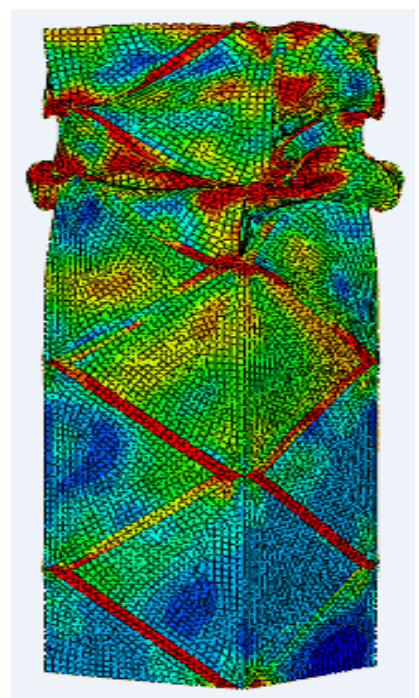

Pattern 3

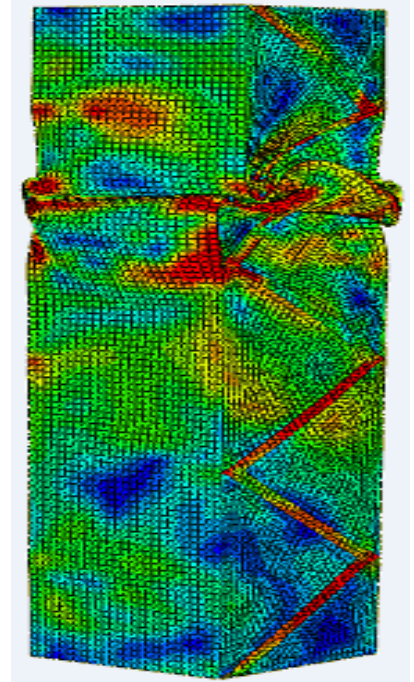

Pattern 4

Figure 23. The failure modes of the square tube with origami pattern with different in dimensions and configuration for axial impact loading

The changes in crush performance indices of square tube with different origami pattern parameters subjected to axial static loading are as shown in Table 3 and it could be seen that pattern 1 gave the highest reduction of IPF by $36.81 \%$ compared to other patterns. The reduction of IPF value showed that the simulation analysis had managed to achieve the purpose of the square tube with origami pattern to reduce the high initial force of the plain/conventional square tube. The patterns' parameters showed that the decreasing in percentage of CFE and SEA occurred because of the reduction of structure's stiffness formed after employing various origami pattern and therefore absorb less energy especially in the earlier crushing process. Hence, it can be concluded that this kind of origami pattern is not suitable for static axial loading of square tubes.

Table 3. Changes in crush performance indices of square tube with different origami pattern parameters subjected to axial static loading

\begin{tabular}{cccccc}
\hline \multirow{2}{*}{ Performance index } & \multirow{2}{*}{ Plain square tube } & \multicolumn{5}{c}{ \% change } \\
& & Pattern 1 & Pattern 2 & Pattern 3 & Pattern 4 \\
\hline IPF & $44488 \mathrm{~N}$ & -36.81 & -20.56 & -25.90 & -17.15 \\
$\mathrm{CFE}$ & $46.37 \%$ & -4.27 & -11.69 & -11.55 & -17.57 \\
$\mathrm{SEA}$ & $24530 \mathrm{~J} / \mathrm{kg}$ & -35.51 & -27.76 & -31.79 & -29.64 \\
\hline
\end{tabular}

Note. The symbol of '+' indicates as increase and '-'indicates as reduction.

The changes in crush performance indices of square tube with different origami pattern parameters subjected to axial impact loading have shown in Table 4 , and it could be observed that by having pattern 1, it had managed to give the highest reduction of IPF by $36.85 \%$ compared to other patterns. Thus, the simulation analysis had managed to achieve the purpose of the square tube with origami pattern by the reducing the IPF of the plain square tube. The patterns parameters also have improve the crush performance by increasing the CFE percentage of the square tube with origami pattern. It was mainly due to the ease in buckling behavior that was suitable for impact loading and made it easier for the square tube to be crashed with lower and uniform force as a result of lowering the IPF and promote the higher energy absorption on the square tube. Hence, it can be concluded that this kind of origami pattern is more suitable for impact loading. 
Table 4. Changes in crush performance indices of square tube with different origami pattern parameters subjected to axial impact loading

\begin{tabular}{cccccc}
\hline \multirow{2}{*}{ Performance index } & \multirow{4}{c}{ \%lain square tube } & \multicolumn{5}{c}{ \% change } \\
& & Pattern 1 & Pattern 2 & Pattern 3 & Pattern 4 \\
\hline IPF & $43193 \mathrm{~N}$ & -36.85 & -18.83 & -31.73 & -15.75 \\
$\mathrm{CFE}$ & $11.93 \%$ & +59.45 & +22.44 & +45.75 & +20.64 \\
$\mathrm{SEA}$ & $5198 \mathrm{~J} / \mathrm{kg}$ & +6.53 & +3.16 & +4.22 & +1.84 \\
\hline
\end{tabular}

Note. The symbol of '+' indicates as increase and '-'indicates as reduction.

\section{Conclusions}

From the impact simulation results, it can be seen that pattern 1 shows the lowest IPF, a reduction of $36.85 \%$ compared to the square tube. Furthermore, pattern 1 also gave the highest value of increase in CFE and SEA compared to the square tube with $59.51 \%$ and $6.53 \%$, respectively. For the static loading, pattern 1 also gave the lowest IPF, a reduction of $36.81 \%$. However, all patterns were unable to improve the CFE and SEA of the square tube which meant that they may not suitable to be employed under axial static loading conditions.

The objective of this research which was to study the energy absorption performance of the square tube with origami pattern loaded statically and dynamically in the axial direction was achieved. Results have shown that the employment of origami pattern on square tube has reduced the initial peak force (IPF) and increased the crush force efficiency (CFE) as well as specific energy absorption (SEA) thus improving the crush performance of the square tube with origami pattern.

\section{References}

Abramowicz, W. (2003). Thin-Walled Structures as Impact Energy Absorbers. Thin-Walled Structures, 91-107. http://dx.doi.org/10.1016/S0263-8231(02)00082-4

Abramowicz, W., \& Jones, N. (1985). Static and Dynamic Axial Crushing of Circular and Square Tubes. Metal Form Impact Mechanical, 225 - 227.

Alghamdi., A. A. A. (2000). Collapsible Impact Energy Absorbers: An Overview. Thin-walled Structures, 189213. http://dx.doi.org/10.1.1.464.9725\&rep=rep1\&type=pdf

Amir, R. A. G., Chong, S. K., Mohd, Z. O., Md, F. S. K., \& Ahmad, M. A. Z. (2013). Impact Response of Multi-Grooved Square Column. Modern Applied Science, Canadian Center of Science and Education, 7(11). http://dx.doi.org/10.5539/mas.v7n11p12

Amir, R. A. G., Lukman, H., \& Hashim, H. (2013). Applied Mechanics and Materials. Impact Response of Circular Tube with Concentric Plunger, 792-798. http://dx.doi.org/10.4028/www.scientific.net/ AMM.275-277.792

Fan, Z., Lu, G., \& Liu, K. (2011). Quasi-static Axial Compression of Thin-Walled Tubes with Different Cross-Sectional Shapes. Engineering Structures, 80-83. http://dx.doi.org/10.1016/j.engstruct.2011.09.020

Jandaghi, S. V., \& Marzbanrad, J. (2012). Analytical and experimental studies on quasi-static axial crush behaviour of thin-walled tailor made aluminum tubes. Thin-Walled Structures, 60, 24-37. http://dx.doi.org/10.1016/j.tws.2012.05.015

Kim, H. C., Shin, D. K., Lee, J. J., \& Kwon, J. B. (2014). Crashworthiness of aluminium/CFRP square hollow section beam under axial load for crash box application. Composite Structures, 112, 1-10. http://dx.doi.org/10.1016/j.compstruct.2014.01.042

Lee, S., Hahn, C., Rhee, M., \& Oh, J. E. (1999). Effect of Triggering on the Energy Absorption Capacity of Axially Compressed Aluminium Tubes. Material and Design, 31-40. http://dx.doi.org/10.1016/S0261-3069(98)00043-0

Lu, G. X., \& Yu, T. X. (2003). Energy Absorption of Structures and Materials. Woodhead.

Ma, Y., Sugahara, T., Yang, Y., \& Hamada, H. A. (2015). Study on the energy absorption properties of carbon/aramid fiber filament winding composite tube. Composite Structures, 123, 301-311.

Nia, A. A., Nejad, K. F., Badnava, H., \& Farhoudi, H. R. (2012). Effects of buckling initiators on mechanical behaviour of thin-walled square tubes subjected to oblique loading. Thin-Walled Structures, 59, 87-96. 
http://dx.doi.org/10.1016/j.tws.2012.03.002

Rahul, R. K., Sharon, K. W., \& Zhong, Y. (2013). Conceptual Study on an Origami Patterns of Type 1 Tapered Square Tub with and without a Crack. Applied Mechanics and Materials, 184-188. http://dx.doi.org/10.1016/j.tws.2007.06.004

Song, J., Chen, Y., \& Lu, G. X. (2012). Axial Crushing of Thin-walled Structures with Origami Patterns. Thin-Walled Structures, 65-71. http://dx.doi.org/10.1080/13588265.2015.1010396

Tarlochan, F., Samer, F., Hamouda, A. M. S., Ramesh, S., \& Khalid, K. (2013). Design of thin wall structures for energy absorption applications: Enhancement of crashworthiness due to axial and oblique impact forces. Thin Walled Structures, 71, 7-17. http://dx.doi.org/10.1016/j.tws.2013.04.003

Yamashita, M., Kenmotsu, H., \& Hattori, T. (2012). Dynamic axial compression of aluminium hollow tubes with hat cross-section and buckling initiator using inertia force during impact. Thin-walled Structure, 50, 37-44. http://dx.doi.org/10.1016/j.tws.2011.10.001

You, Z., \& Cole, N. (2006). Self-Locking Bi-Stable Deployable Booms. AIAA, 1685.

Zhang, X. W., Su, H., \& Yu, T. X. (2008). Energy Absorption of an Axially Crushed Square Tube with a Buckling Initiator. International Journal of Impact Engineering. http://dx.doi.org/10.1016/j.ijimpeng.2008.02.002

Zhang, X., Cheng, G. D., You, Z., \& Zhang, H. (2007). Energy Absorption of Axially Compressed Thin-Walled Square Tubes with Patterns. Thin-Walled Structures, 737-746. http://dx.doi.org/10.1016/j.tws.2007.06.004

\section{Copyrights}

Copyright for this article is retained by the author(s), with first publication rights granted to the journal.

This is an open-access article distributed under the terms and conditions of the Creative Commons Attribution license (http://creativecommons.org/licenses/by/3.0/). 